\section{Efficacy of radioembolization according to tumor morphology and portal vein thrombosis in intermediate-advanced hepatocellular carcinoma}

\author{
Rita Golfieri', Cristina Mosconi ${ }^{* 1}$, Alberta Cappelli', Emanuela Giampalma', \\ Maria Cristina Galaverni', Cinzia Pettinato², Matteo Renzulli', Fabio Monari', \\ Bruna Angelelli', Patrizia Pini', Eleonora Terzi ${ }^{4}$, Salvatore Ascanio', Giorgio Garzillo', \\ Fabio Piscaglia ${ }^{4}$, Luigi Bolondi ${ }^{4} \&$ Franco Trevisani ${ }^{5}$
}

Purpose: We analyzed overall survival (OS) following radioembolization according
to macroscopic growth pattern (nodular vs infiltrative) and vascular invasion in
intermediate-advanced hepatocellular carcinoma (HCC). Methods: Between September
2005 and November 2013,104 patients $(50.0 \%$ portal vein thrombosis [PVT], $29.8 \%$ infiltrative
morphology) were treated. Results: Median OS differed significantly between patients with
segmental and lobar or main PVT ( $p=0.031$ ), but was 17 months in both those with patent
vessels and segmental PVT. Median OS did not differ for infiltrative and nodular HCC. Median
OS was prolonged in patients with a treatment response at 3 months $(p=0.023)$. Prior
TACE was also a significant predictor of improved OS. Conclusion: A further indication for
radioembolization might be infiltrative HCC, since OS was similar to nodular types.

Loco-regional therapies are well established for the management of hepatocellular carcinoma (HCC) in patients with sufficient liver function reserve (Child-Pugh A or Child-Pugh B) and limited cancer-related symptoms (Eastern Cooperative Oncology Group [ECOG] performance status 0 or $\leq 1$ in advanced stage disease). Treatments are tailored according to cancer stage. Highly focal ablative therapies such as radiofrequency ablation, for example, are used as an alternative to surgery in early stage HCC (Barcelona Clinic Liver Cancer staging [BCLC] stage O/A) in patients with limited number (less than three) of small lesions $(\leq 3 \mathrm{~cm})$; or combined with transarterial chemoembolization (TACE) to reduce local relapses in patients with tumors diameter between 3 and $5 \mathrm{~cm}$, radiofrequency ablation [1]. Transarterial therapies such as TACE [2] or radioembolization (RE) [3,4] are recommended for the management of intermediate (BCLC stage B) or advanced HCC (BCLC stage C), especially in patients where the cancer remains predominantly localized to liver. However locally advanced HCC is characterized by widely varying tumor burden, macroscopic growth pattern ('nodular', 'massive' and 'infiltrative' $[5,6]$ ) with or without invasion of the portal trunk or main branch (portal vein tumor thrombosis [PVT]). Data on the presentation, treatment and outcome of patients according to tumor growth patterns and extent of vascular invasion are not well characterized. The wide interval of expected survival after TACE, varying from 14 to 45 months [2], suggests that some patients may benefit from alternative treatment options in this setting.

Radioembolization is a form of brachytherapy utilizing intra-arterially injected resin or glass microspheres loaded with yttrium- $90\left({ }^{90} \mathrm{Y}\right)$ as sealed sources of radiation. The high-energy $\beta$ radiation from

'Radiology Unit, Department of Diagnostic \& Preventive Medicine, S Orsola-Malpighi Hospital, Bologna, Italy

${ }^{2}$ Medical Physics Unit, Radiology Unit, S Orsola-Malpighi Hospital, Bologna, Italy

${ }^{3}$ Radiation Oncology Unit, Radiology Unit, S Orsola-Malpighi Hospital, Bologna, Italy

${ }^{4}$ Department of Medical \& Surgical Sciences, University of Bologna, Bologna, Italy

${ }^{5}$ Department of Medical \& Surgical Sciences, Alma Mater Studiorum - University of Bologna, Bologna, Italy

*Author for correspondence: cristina.mosconi@aosp.bo.it

\section{KEYWORDS}

- ${ }^{0}$ Y-radioembolization

- infiltrative

hepatocellular carcinoma

- intermediate-advanced

hepatocellular carcinoma

- portal vein tumor

thrombosis 
${ }^{90} \mathrm{Y}$ has limited tissue penetration $(2.5 \mathrm{~mm})$ and short half-life (2.67 days). Within 2 weeks after injection, $>95 \%$ of the radiation is deposited. The absorbed dose of ${ }^{90} \mathrm{Y}$ in tumor tissue depends on the intratumoral vessel density, which varies according to tumor type [7]. Despite this heterogeneity, microspheres are preferentially delivered to the tumor vasculature in a $3: 1$ to $20: 1$ ratio compared with the normal liver. The small size of microspheres ( $30 \mu \mathrm{m}$ diameter) means that they are carried into the microvasculature, where a radiation dose ( $>500 \mathrm{~Gy})[8,9]$ has a largely localized effect, and little or no macroembolic effect [10]. By contrast, the embolic proprieties of the larger $(100-500 \mu \mathrm{m})$ drug-eluting particles needed for TACE [2], means that compromised portal vein blood flow is considered a relative contraindication [11] leading to an increased risk of liver decompensation [12].

The aim of this study was to assess the efficacy and safety of ${ }^{90} \mathrm{Y}$ resin microspheres $\left[{ }^{90} \mathrm{Y}-\mathrm{RE}\right]$ (SIR-Spheres ${ }^{\circledR}$; Sirtex Medical Limited, Sydney, Australia) in unresectable HCC patients, according to the extent of PVT and tumor morphology (nodular or infiltrative) as depicted by computed tomography (CT) and/or MRI [13].

\section{Methods}

A retrospective analysis was carried out on unresectable HCC patients treated with ${ }^{90} \mathrm{Y}-\mathrm{RE}$ at a single tertiary care center between September 2005 and November 2013. Authorization for the analysis was received from the local review board and patients were followed from the date of treatment until June 2014 or until death. Tumor morphology and tumor PVT was confirmed by CT and/or MRI. Based on the location and extent of tumor thrombi, PVT was classified as: PVT-0: patent portal vein; PVT-1: segmental branches of portal vein, PVT-2: left or right portal vein and PVT-3: main portal vein trunk [14]. The presence of infiltrative disease was confirmed by CT/MRI appearance according to the current imaging criteria [15].

\section{- Pretreatment evaluation}

All patients provided informed consent. The decision to treat patients with ${ }^{90} \mathrm{Y}-\mathrm{RE}$ was made by the multidisciplinary team only after a detailed pretreatment work-up. ${ }^{90} \mathrm{Y}-\mathrm{RE}$ was considered in patients unsuitable for (and/or had failed prior) radical, transarterial or systemic therapy. All patients who received ${ }^{90} \mathrm{Y}$-RE had a confirmed diagnosis of $\mathrm{HCC}$ [11] and an ECOG performance status score $0-2$. We excluded patients with tumor volume $>50 \%$ of the liver volume, significant extrahepatic disease, abnormal organ or bone marrow function and total bilirubin level $>2.0 \mathrm{mg} / \mathrm{dl}$ in the absence of a reversible cause, limited hepatic reserve (Child-Pugh score $>7$ ), ascites or other clinical signs of liver failure [16].

A total body quadriphasic CT was performed to identify target lesions and to evaluate the liver and tumor volume for the subsequent calculation of the radiation dose. The hepatic arterial anatomy was assessed by selective coeliac and superior mesenteric arteriography and a nontarget vessel microcoils embolization was performed to ensure the safe delivery of microspheres to the liver only. Once identified the optimal site for microsphere injection, $150 \mathrm{MBq}$ of technetium99m-labeled-macroaggregated albumin (99mTcMAA) was administered through the angiographic catheter in place. A planar scintigraphy was obtained to calculate hepatopulmonary shunts (lung shunt fraction should not exceed $20 \%$ ) and to exclude any possible extrahepatic uptake. Just after the planar study, a single photon emission computed tomography was performed to visualize the particles distribution over the liver, as a pretreatment simulation study.

With the data obtained from the liver volume on CT, the body surface area methodology was used to calculate the activity of ${ }^{90}$ Y-resin microspheres [17]. Within 14 days, selective/superselective intra-arterial infusion of ${ }^{90} \mathrm{Y}$-resin microspheres was performed according to the preset dose, and targeted treatment confirmed by CT/PET. In cases of bilobar disease, treatment was mostly performed using a sequential multisegmental approach during the same session.

\section{- Statistical analyzes}

SAS version 9.2 XP Pro statistical analyzes software (SAS Institute Inc., NC, USA) was used for all calculations. Kaplan-Meier nonparametric methodology estimated survival. Survival was assessed from day of first treatment procedure until death or last follow-up when data were censored. Univariate Cox proportional hazards models were applied to identify single-vector prognostic factors associated with survival, and a log-rank test compared survival curves among strata.

\section{Results}

In total, 104 consecutive patients received ${ }^{90} \mathrm{Y}$ RE. Approximately $60 \%$ had advanced (BCLC 
Table 1. Baseline disease and tumor

\section{characteristics.}

Characteristics $\quad \mathrm{n}(\%)$

Gender:

- Male:female

87 (83.7):17 (16.3)

Age (years):

- Mean \pm SD (range) $\quad 66.0 \pm 9.4(22-84)$

$-\geq 70$ years $45(43.3)$

ECOG performance status:

$-0$

$91(87.5)$

-1 or 2

$13(12.5)$

Prior procedures ${ }^{\dagger}$

- Surgery $20(19.2)$

- Vascular 47 (45.2)

- Percutaneous ablation 17 (9.2)

Prior sorafenib 11 (10.6)

Cirrhosis:

- Viral (HCV/HBV) $84(80.8)^{\ddagger}$

- Alcohol 11 (10.6)

- Other 9 (8.6)

Child-Pugh class:

$-5 \quad 66(63.5)$

$-6 \quad 33(31.7)$

$\begin{array}{ll}-7 & 5(4.8)\end{array}$

Tumor burden (nodules):

$-1 \quad 30(28.8)$

$-2-5 \quad 45(43.3)$

$->5 \quad 29(27.9)$

Maximum lesion length:

$-0-50 \mathrm{~mm} \quad 36(34.9)$

$-\geq 51 \mathrm{~mm} \quad 67(65.1)^{5}$

${ }^{\dagger}$ Prior procedures include surgery (resection or

transplantation); percutaneous ablation (radiofrequency or

ethanol injection) and intra-arterial procedures (transarterial

embolization, chemoembolization or hepatic arterial

chemotherapy.

${ }^{*}$ Hepatitis C: 62 (60.2\%).

s>10 mm: 6 (5.8\%).

'Sites of extrahepatic disease included mainly lymph nodes: 25

(24.0\%) but also other sites in three patients.

BCLC: Barcelona clinic liver cancer; CLIP: The Cancer of Liver

Italian Program; HBV: Hepatitis B virus; HCV: Hepatitis C virus;

INR: International normalized ratio; SD: Standard deviation.

stage C) HCC and $51.0 \%$ had at least one prior procedure (mainly TACE) (Table 1). Cirrhosis of viral etiology $(\mathrm{HCV} / \mathrm{HBV})$ was identified in $80.8 \%$ of patients. Prominent features were large lesion length beyond $51 \mathrm{~mm}$ (65.1\%), multinodular disease $>$ five lesions $(27.9 \%)$, PVT (50.0\%), infiltrative tumor morphology (29.8\%); alpha-fetoprotein levels >400 ng/ml (35.3\%), bilobar disease $(47.1 \%)$ and extrahepatic disease, mainly restricted to lymph nodes (27.9\%).

A median activity of $1.6 \mathrm{GBq}$ of ${ }^{90} \mathrm{Y}$ was administered as either a super-selective segmental or lobar procedure in 56.7 and $42.3 \%$ of

\begin{tabular}{|c|c|}
\hline Characteristics & n (\%) \\
\hline Bilobar & 49 (47.1) \\
\hline Extra-hepatic metastases & $29(27.9)^{9}$ \\
\hline $\begin{array}{l}\text { Portal vein thrombosis: } \\
-0 \text { - patent } \\
-1 \text { - segmental } \\
-2 \text { - right/left portal } \\
-3 \text { - main portal }\end{array}$ & $\begin{array}{l}52(50.0) \\
26(25.0) \\
13(12.5) \\
13(12.5)\end{array}$ \\
\hline $\begin{array}{l}\text { Tumor morphology: } \\
\text { - Infiltrative } \\
\text { - Nodular }\end{array}$ & $\begin{array}{l}31(29.8) \\
73(70.2)\end{array}$ \\
\hline $\begin{array}{l}\text { BCLC stage: } \\
-A \\
-B \\
-C\end{array}$ & $\begin{array}{l}4(3.8) \\
38(36.5) \\
62(59.6)\end{array}$ \\
\hline $\begin{array}{l}\text { CLIP: } \\
-0 \\
-1 \\
-2 \\
-3 \text { and } 4\end{array}$ & $\begin{array}{l}14(13.7) \\
42(41.2) \\
35(34.3) \\
11(10.8)\end{array}$ \\
\hline Alfa-fetoprotein (>400 ng/ml) & $36(35.3)$ \\
\hline $\begin{array}{l}\text { Total bilirubin (mg/dl); mean } \\
\pm S D\end{array}$ & $1.0 \pm 0.55$ \\
\hline Albumin (mg/dl); mean \pm SD & $4.4 \pm 4.88$ \\
\hline $\begin{array}{l}\text { INR: } \\
- \text { Mean } \pm \text { SD } \\
->1.2\end{array}$ & $\begin{array}{l}1.2 \pm 0.14 \\
27(26.2)\end{array}$ \\
\hline $\operatorname{ALT}(\mathrm{U} / \mathrm{I}) ;$ mean $\pm \mathrm{SD}$ & $62.2 \pm 46.17$ \\
\hline Creatinine $(\mathrm{mg} / \mathrm{dl})$; mean $\pm \mathrm{SD}$ & $0.9 \pm 0.26$ \\
\hline \multicolumn{2}{|c|}{$\begin{array}{l}\text { †Prior procedures include surgery (resection or } \\
\text { transplantation); percutaneous ablation (radiofrequency or } \\
\text { ethanol injection) and intra-arterial procedures (transarterial } \\
\text { embolization, chemoembolization or hepatic arterial } \\
\text { chemotherapy. } \\
\text { †Hepatitis C: } 62 \text { (60.2\%). } \\
\text { '>10 mm: } 6 \text { (5.8\%). } \\
\text { 'Sites of extrahepatic disease included mainly lymph nodes: } 25 \\
\text { (24.0\%) but also other sites in three patients. } \\
\text { BCLC: Barcelona clinic liver cancer; CLIP: The Cancer of Liver } \\
\text { Italian Program; HBV: Hepatitis B virus; HCV: Hepatitis C virus; } \\
\text { INR: International normalized ratio; SD: Standard deviation. }\end{array}$} \\
\hline
\end{tabular}

patients, respectively (Table 2). Nontarget vessels were embolized in $20.2 \%$ of patients (Table 2 ). Median lung shunting was $5.0 \%$ (interquartile range: $3.0 \%$ ). Patent vessels and segmental PVT were more common in patients with nodular HCCs than in patients with infiltrative HCC: $83.1 \%$ (59 of 71 ) versus $58.1 \%$ (18/31) (Table 3).

\section{- Kaplan-Meier analyzes of overall survival} Table 3 \& Figure 1 outline the Kaplan-Meier analyzes for overall survival (OS). These results show that patients with segmental PVT-1 had similar OS as those with patent portal vein (median 17.0 months in both groups), but OS 
Table 2. Treatment parameters.

\begin{tabular}{ll} 
Characteristics & $\mathbf{n}(\%)$ \\
Activity administered (GBq); median (range) & $1.6(0.5-2.4)$ \\
Target treatment: & \\
- Whole liver & $1(1.0)$ \\
- Right lobe & $34(32.7)$ \\
- Left lobe & $10(9.6)$ \\
- Multisegmental & $26(25.0)$ \\
- Segmental & $33(31.7)$ \\
Target tumor volume (ml); median (range) & $267.9(6.9-1678)$ \\
Target liver volume (ml); median (range) & $929.4(212-3217)$ \\
Embolization: & \\
- None & $83(79.8)$ \\
- Gastroduodenal artery or left gastric & $16(15.4)$ \\
- Other & $5(4.8)$ \\
\hline
\end{tabular}

differed significantly between patients with segmental PVT-1 and left/right or main PVT (PVT-2 or $-3 ; \mathrm{p}=0.031$ ) (Figure 1A). Comparison of patients with infiltrative and nodular pattern of HCC found no significant difference in OS (Figure 1B \& Figure 1C).

Univariate analyzes confirmed that survival was primarily a function of disease stage (particularly the presence or absence of PVT) and liver function, rather than either size, number, distribution or morphology of liver lesions. Median OS was significantly prolonged in the patients with a treatment response at 3 months (complete or partial response or stable disease according to modified Response Evaluation Criteria in Solid Tumors (mRECIST) [18]) compared with patients with progressive disease $(\mathrm{p}=0.023)$ (Figure 1D). Prior TACE was also a significant predictor of improved OS (Table 3).

Figure 2 illustrates an example of response observed at 3 months and 1 year after ${ }^{90} \mathrm{Y}$-RE in a patient with infiltrative HCC in the VIII segment with associated tumor thrombosis of the segmental portal branch.

\section{- Cumulative mortality}

Cumulative mortality rates in patients with patent portal vein (PVT-0) and segmental PVT-1 were: 61.5 and $48.1 \%$ at 1 year, and 63.4 and $38.5 \%$ at 3 years post-treatment, respectively. In patients with left/right or main PVT (PVT-2 or PVT-3), cumulative mortality rates were: 38.5 and $23.1 \%$ at 1 year and 30.8 and $23.1 \%$ at 3 years, respectively.

\footnotetext{
- Safety

${ }^{90} \mathrm{Y}-\mathrm{RE}$ was well-tolerated in this cohort of patients. Severe events (CTCAE grade 3/4) reported
}

within 3 months of treatment were: fever $(\mathrm{n}=1)$, pneumonia $(\mathrm{n}=5)$, fatigue $(\mathrm{n}=2)$, cholecystitis $(n=3)$ and ascites $(n=6)$. Median total bilirubin levels were similar in patients with PVT-0 versus those with PVT-1, -2, -3 at 1 month post-treatment: $1.1 \mathrm{mg} / \mathrm{dl}$ (range: $0.3-3.4 \mathrm{mg} / \mathrm{dl}$ ) versus 1.1 (range: $0.3-21.9 \mathrm{mg} / \mathrm{dl}$ ); and 3 months posttreatment: $1.3 \mathrm{mg} / \mathrm{dL}$ (range: $0.3-10.0 \mathrm{mg} / \mathrm{dl}$ ) versus 1.4 (range: $0.3-20.0 \mathrm{mg} / \mathrm{dl}$ ).

\section{Discussion}

Our results confirm that survival after ${ }^{90} \mathrm{Y}-\mathrm{RE}$ is strictly related to BCLC stage and liver function. Response to ${ }^{90} \mathrm{Y}-\mathrm{RE}$ at 3 months was predictive of longer survival.

There is good evidence from large series [19] to consider some patients with PVT and/or multifocal disease and sufficient liver reserve (hitherto only eligible for systemic treatment) as potential candidates for ${ }^{90} \mathrm{Y}-\mathrm{RE}$. Our results show that survival varied by location of PVT, but ${ }^{90} \mathrm{Y}-\mathrm{RE}$ was equally well tolerated in patients with and without PVT. ${ }^{90} Y-R E$ yielded similar OSs in patients with segmental PVT and patients with patent portal vein, but OS were significantly diminished in patients with advanced BCLC stage C disease with lobar or main PVT, irrespective of tumor morphology.

Comparing the 1-year cumulative survival according to the extent of PVT (types $1 / 2 / 3$ ), ${ }^{90} Y-R E$ (1-year survival 63.4\%/38.5\%/30.8\%) compared favorably with surgical resection/conformal radiotherapy combined with TACE $(\mathrm{n}=371 ; 55.9 \% / 46.9 \% / 28.1 \%)$ [20] and TACE alone (41.1\%/37.9\%/30.4\%) [21]. The 3-year cumulative survivals in this cohort suggested a greater durability of response with ${ }^{90} \mathrm{Y}-\mathrm{RE}(38.5 \% / 23.1 \% / 23.1 \%)$ than with TACE alone based on data from published case series (8.9\%/6.0\%/4.2\%) [21] for PVT types $1 / 2 / 3$, respectively. This study suggests that microembolic therapies such as ${ }^{90} \mathrm{Y}$-RE may be an effective and well-tolerated alternative to TACE in this setting.

We found that prior TACE was a predictor of prolonged survival compared with treatment of naive patients ( 27 vs 9 months), which may be a reflection of the better prognosis for patients who were eligible for TACE. Some reports have suggested that postoperative TACE prolongs survival following liver resection combined with thrombectomy [22], especially for patients with main PVT, with sufficient liver reserve. Equally our results suggest that further 
Table 3. Kaplan-Meier analysis of survival for parameters of disease stage, tumor burden and morphology and prior treatments.

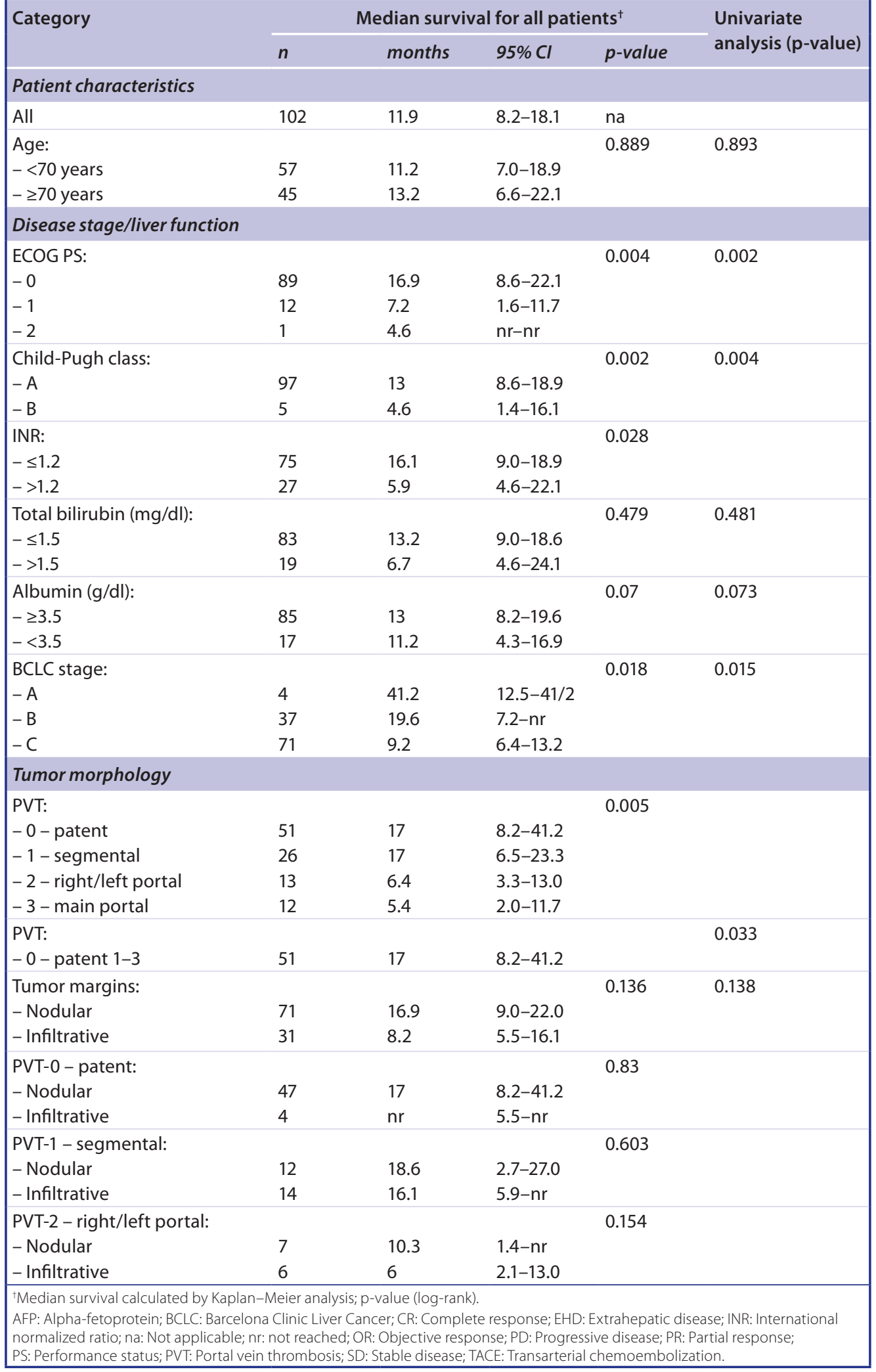


Table 3. Kaplan-Meier analysis of survival for parameters of disease stage, tumor burden and morphology and prior treatments (cont.).

\begin{tabular}{|c|c|c|c|c|c|}
\hline \multirow[t]{2}{*}{ Category } & \multicolumn{4}{|c|}{ Median survival for all patients ${ }^{\dagger}$} & \multirow{2}{*}{$\begin{array}{l}\text { Univariate } \\
\text { analysis ( } p \text {-value) }\end{array}$} \\
\hline & $n$ & months & $95 \% \mathrm{Cl}$ & $p$-value & \\
\hline \multicolumn{6}{|l|}{ Tumor morphology (cont.) } \\
\hline $\begin{array}{l}\text { PVT-3 - main portal: } \\
\text { - Nodular } \\
\text { - Infiltrative }\end{array}$ & $\begin{array}{l}5 \\
7\end{array}$ & $\begin{array}{l}11.5 \\
4.1\end{array}$ & $\begin{array}{l}5.1-24.0 \\
1.7-9.2\end{array}$ & 0.168 & \\
\hline \multicolumn{6}{|l|}{ Tumor burden } \\
\hline $\begin{array}{l}\text { Number of nodules: } \\
-1-5 \\
->5\end{array}$ & $\begin{array}{l}74 \\
28\end{array}$ & $\begin{array}{l}13.2 \\
8.2\end{array}$ & $\begin{array}{l}13.6-22.1 \\
5.1-18.6\end{array}$ & 0.259 & 0.172 \\
\hline $\begin{array}{l}\text { Bilobar: } \\
\text { - No } \\
\text {-Yes }\end{array}$ & $\begin{array}{l}55 \\
47\end{array}$ & $\begin{array}{l}13 \\
11.2\end{array}$ & $\begin{array}{l}8.1-18.6 \\
7.0-24.0\end{array}$ & 0.958 & 0.958 \\
\hline $\begin{array}{l}\text { EHD: } \\
\text { - No } \\
\text { - Yes }\end{array}$ & $\begin{array}{l}73 \\
29\end{array}$ & $\begin{array}{l}13.2 \\
9.2\end{array}$ & $\begin{array}{l}8.2-18.9 \\
4.6-23.3\end{array}$ & 0.87 & 0.871 \\
\hline $\begin{array}{l}\text { Maximum lesion length: } \\
-0-50 \mathrm{~mm} \\
-\geq 51 \mathrm{~mm}\end{array}$ & $\begin{array}{l}34 \\
67\end{array}$ & $\begin{array}{l}11.9 \\
12.5\end{array}$ & $\begin{array}{l}5.4-18.1 \\
7.2-22.1\end{array}$ & 0.332 & 0.033 \\
\hline \multicolumn{6}{|c|}{ Radioembolization procedure } \\
\hline $\begin{array}{l}\text { Treatment target: } \\
\text { - Whole } \\
\text { - Right } \\
\text { - Left } \\
\text { - Multisegmental } \\
\text { - Segmental }\end{array}$ & $\begin{array}{l}1 \\
33 \\
10 \\
25 \\
33\end{array}$ & $\begin{array}{l}19.6 \\
9 \\
11.1 \\
17 \\
17\end{array}$ & $\begin{array}{l}\mathrm{nr}-\mathrm{nr} \\
5.4-16.1 \\
2.0-24.1 \\
5.9-23.3 \\
7.0-\mathrm{nr}\end{array}$ & 0.52 & \\
\hline $\begin{array}{l}\text { OR at } 3 \text { months: } \\
-C R / P R / S D \\
-P D\end{array}$ & $\begin{array}{l}35 \\
34\end{array}$ & $\begin{array}{l}23.3 \\
11.7\end{array}$ & $\begin{array}{l}13.2-41.2 \\
7.1-18.6\end{array}$ & 0.032 & 0.035 \\
\hline \multicolumn{6}{|l|}{ Prior treatment } \\
\hline $\begin{array}{l}\text { Prior TACE: } \\
- \text { Yes } \\
- \text { No }\end{array}$ & $\begin{array}{l}20 \\
82\end{array}$ & $\begin{array}{l}27 \\
9\end{array}$ & $\begin{array}{l}16.0-\mathrm{nr} \\
6.6-13.0\end{array}$ & 0.003 & 0.004 \\
\hline
\end{tabular}

research with ${ }^{90} \mathrm{Y}-\mathrm{RE}$ in this setting would be valuable.

Our study demonstrates that there was no significant difference in survival between patients with nodular and infiltrative HCC, the latter being associated to PVT for the vast majority of patients $(87 \%)$. Though infiltrative HCC is relatively common (accounting for
$7-20 \%$ of HCC cases [15,23], there are limited published data with either sorafenib or locoregional treatments in this setting [24-28]. The weak demarcation against the background of the cirrhotic liver and the difficulty in defining the extent of infiltrative HCC on imaging often impedes early diagnosis and adequate targeting for locoregional treatment as well as

Figure 1. Kaplan-Meier analyses of overall survival (see facing page). Kaplan-Meier analyses of overall survival stratified according to: (A) the location and extent of tumor thrombi (PVT); (B) tumor growth patterns (infiltrative or nodular); (C) tumor growth patterns (infiltrative or nodular) in patients with or without left/right or main PVT; (D) treatment response according to mRECIST at 3 months. CR: Complete response; NA: Not available; PD: Progressive disease; PR: Partial response; PVT: Portal vein thrombosis; SD: Stable disease. 

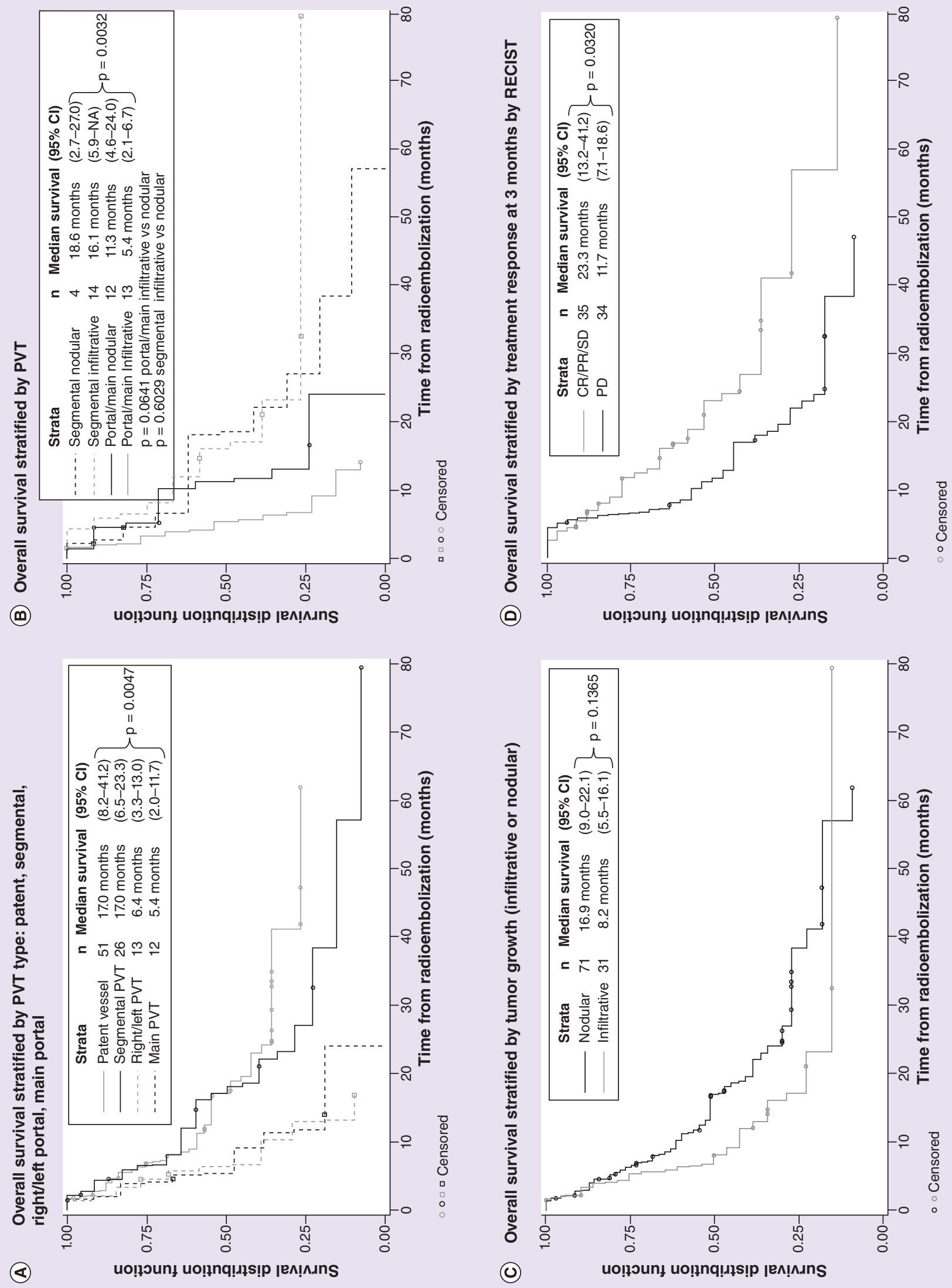

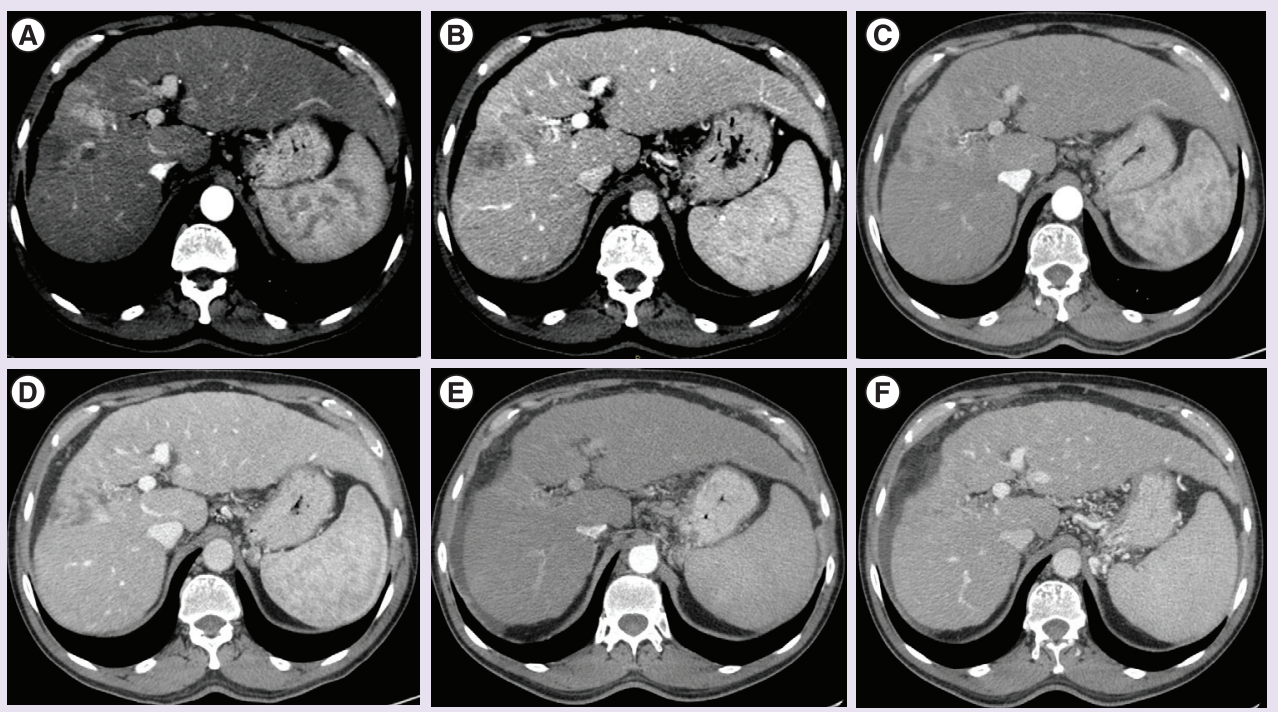

Figure 2. Computed tomography evaluation of ${ }^{90} \mathrm{Y}$-radioembolization response. The pretreatment computed tomography showing infiltrative hepatocellular carcinoma in the VIII segment with associated tumor thrombosis of the segmental portal branch as visualized in (A) the arterial phase and (B) the portal-venous phase. (C \& D) Computed tomography performed after 3 months from the treatment showing both a significant decrease of the enhancement of the portal venous thrombus and a reduction of the enlargement of the portal branch as sign of response. (E \& F) This is better visualized at 1 year. Note the significant 'shrinkage' of the VIII segment.

determining the subsequent treatment response. Infiltrative HCC has been traditionally considered a contraindication for TACE due to its poor outcomes $[29,30]$. In spite of this, investigators from Johns Hopkins University School of Medicine [31] recently determined in a large case series that intra-arterial therapy was well tolerated and extended the median survival to 12 months, compared with 3 months with best supporting care. In a further evaluation of 128 patients with infiltrative HCC treated with curative intent TACE plus cisplatin hepatic arterial infusion [26], prolonged survival ( $>2$ years) was evident in a sub-set of patients with preserved hepatic function (Child-Pugh A vs B). Those patients with a high tumor burden (defined by $50 \%$ of the liver volume or high serum ALP level of $130 \mathrm{IU} / \mathrm{l}$ ) had a poor prognosis after TACE.

\section{Conclusion}

In conclusion, our analysis shows that HCCs complicated by segmental PVT can be effectively treated with ${ }^{90} \mathrm{Y}-\mathrm{RE}$, with similar response as in patent portal vein. Moreover, infiltrative HCCs may be considered as a further indication for ${ }^{90} \mathrm{Y}-\mathrm{RE}$, since survivals were similar to nodular types. This analysis should encourage further prospective study of ${ }^{90} \mathrm{Y}-\mathrm{RE}$ in this treatment setting, because there are so few effective treatment options. Prior TACE was not a contraindication, but in fact appeared to be a positive predictor of survival in our study. Treatment response at 3 months was also a predictor for longer survival.

\section{Acknowledgements}

The authors would like to thank Mark Van Buskirk for his statistical work and advice. The authors would like to thank Rae Hobbs for her editorial assistance.

Financial \& competing interests disclosure An educational grant was provided by Sirtex Medical Ltd to aid in the analysis of data and the editing of the manuscript. The authors have no other relevant affiliations or financial involvement with any organization or entity with a financial interest in or financial conflict with the subject matter or materials discussed in the manuscript apart from those disclosed.

No writing assistance was utilized in the production of this manuscript.

\section{Ethical conduct of research}

The authors state that they have obtained appropriate institutional review board approval or have followed the 
principles outlined in the Declaration of Helsinki for all human or animal experimental investigations. In addition, for investigations involving human subjects, informed consent has been obtained from the participants involved.

\section{Open access}

This work is licensed under the Attribution-NonCommercial-

NoDerivatives 4.0 Unported License. To view a copy of this

license, visit http://creativecommons.org/licenses/

by-nc-nd/4.0/

\section{EXECUTIVE SUMMARY}

- A wide range of loco-regional therapeutic approaches are being developed for hepatocellular carcinoma (HCC) because it is predominantly a liver-limited cancer.

- Expected survivals after standard-of care treatment with transarterial chemoembolization vary widely, from 14 to 45 months in patients with intermediate (Barcelona Clinic Liver Cancer stage B) and suggest that some patients may benefit from alternative treatment options.

- Locally advanced HCC is characterized by varying tumor burden and macroscopic growth pattern ('nodular,' 'massive' and 'infiltrative') which is further complicated by pattern and extent of invasion into the portal trunk or main branch (portal vein thrombosis [PVT]).

- The aim of this study was to evaluate the presentation, treatment and outcome of patients according to tumor growth patterns and extent of vascular invasion following radioembolization.

- Our results confirm that survival after radioembolization is strictly related to Barcelona Clinic Liver Cancer stage and liver function. Response to radioembolization at 3 months was predictive of longer survival.

- There is good evidence from large series to consider some patients with PVT and/or multifocal disease and sufficient liver reserve (hitherto only eligible for systemic treatment) as potential candidates for radioembolization. Our study confirms that HCCs complicated by segmental PVT can be effectively treated with radioembolization, with similar response as in patent portal vein. Radioembolization was equally well-tolerated in patients regardless of the extent of PVT (ischemic hepatitis).

- Infiltrative HCCs may be considered as a further indication for radioembolization, since survivals were similar to nodular types.

- This study provides evidence for the value of microembolic brachytherapies, such as ${ }^{90} Y$-radioembolization, as an effective and well-tolerated alternative to transarterial chemoembolization in this setting; although further prospective studies are needed.

\section{References}

Papers of special note have been highlighted as:

- of interest; $\bullet$ of considerable interest

1 Greten TF, Malek NP, Schmidt S et al. [Diagnosis of and therapy for hepatocellular carcinoma]. Z. Gastroenterol. 51(11), 1269-1326 (2013).

2 Yonenaga N, Kenjo E, Asai T et al. RGDbased active targeting of novel polycation liposomes bearing siRNA for cancer treatment. J. Control. Release 160(2), 177-181 (2012).

3 Thomas MB, Jaffe D, Choti MM et al. Hepatocellular carcinoma: consensus recommendations of the National Cancer Institute Clinical Trials Planning Meeting. J. Clin. Oncol. 28(25), 3994-4005 (2010).

4 Verslype C, Rosmorduc O, Rougier P. Hepatocellular carcinoma: ESMO-ESDO Clinical Practice Guidelines for diagnosis, treatment and follow-up. Ann. Oncol. 23(Suppl. 7), vii41-vii48 (2012).
5 Trevisani F, Caraceni P, Bernardi M et al. Gross pathologic types of hepatocellular carcinoma in Italian patients. Relationship with demographic, environmental, and clinical factors. Cancer 72(5), 1557-1563 (1993).

6 Okuda K, Noguchi T, Kubo Y, Shimokawa Y, Kojiro M, Nakashima T. A clinical and pathological study of diffuse type hepatocellular carcinoma. Liver 1(4), 280-289 (1981).

7 Kennedy AS, Kleinstreuer C, Basciano CA, Dezarn WA. Computer modeling of yttrium-90-microsphere transport in the hepatic arterial tree to improve clinical outcomes. Int. J. Radiat. Oncol. Biol. Phys. 76(2), 631-637 (2010).

8 Kennedy AS, Nutting C, Coldwell D, Gaiser J, Drachenberg C. Pathologic response and microdosimetry of $(90) \mathrm{Y}$ microspheres in man: review of four explanted whole livers. Int. J. Radiat. Oncol. Biol. Phys. 60(5), 1552-1563 (2004).
9 Riaz A, Kulik L, Lewandowski RJ et al. Radiologic-pathologic correlation of hepatocellular carcinoma treated with internal radiation using yttrium-90 microspheres. Hepatology 49(4), 1185-1193 (2009).

10 Salem R, Mazzaferro V, Sangro B. Yttrium 90 radioembolization for the treatment of hepatocellular carcinoma: biological lessons, current challenges, and clinical perspectives. Hepatology 58(6), 2188-2197 (2013).

- This reference provides an excellent summary of the differences in mechanism of action between transarterial chemoembolization and radioembolization.

11 Bruix J, Sherman M. Management of hepatocellular carcinoma: an update. Hepatology 53(3), 1020-1022 (2011).

12 Chan AO, Yuen MF, Hui CK, Tso WK, Lai CL. A prospective study regarding the complications of transcatheter intraarterial 
lipiodol chemoembolization in patients with hepatocellular carcinoma. Cancer 94(6), 1747-1752 (2002).

13 Kanematsu M, Semelka RC, Leonardou P, Mastropasqua M, Lee JK. Hepatocellular carcinoma of diffuse type: MR imaging findings and clinical manifestations. J. Magn. Reson. Imaging 18(2), 189-195 (2003).

14 Shi J, Lai EC, Li N et al. Surgical treatment of hepatocellular carcinoma with portal vein tumor thrombus. Ann. Surg. Oncol. 17(8), 2073-2080 (2010).

- This reference outlines the classification of portal vein thrombosis (used in this study) according to the extent of the tumor thrombus.

15 Reynolds AR, Furlan A, Fetzer DT et al. Infiltrative hepatocellular carcinoma: what radiologists need to know. Radiographics 35(2), 371-386 (2015).

16 Coldwell D, Sangro B, Wasan H, Salem R, Kennedy A. General selection criteria of patients for radioembolization of liver tumors: an international working group report. Am. J. Clin. Oncol. 34(3), 337-341 (2011).

17 Kennedy A, Nag S, Salem R et al. Recommendations for radioembolization of hepatic malignancies using yttrium-90 microsphere brachytherapy: a consensus panel report from the radioembolization brachytherapy oncology consortium. Int. J. Radiat. Oncol. Biol. Phys. 68(1), 13-23 (2007).

18 Kim MN, Kim BK, Han KH, Kim SU. Evolution from WHO to EASL and mRECIST for hepatocellular carcinoma: considerations for tumor response assessment. Expert Rev. Gastroenterol. Hepatol. doi:10.1586/ 17474124.2015.959929 1-14 (2014).
19 Sangro B, Carpanese L, Cianni R et al. Survival after yttrium-90 resin microsphere radioembolization of hepatocellular carcinoma across Barcelona Clinic Liver Cancer stages: a European evaluation. Hepatology 54(3), 868-878 (2011).

.• This study was important given its multicenter nature, defining the survival and safety of radioembolization in hepatocellular carcinoma according to Barcelona Clinic Liver Cancer stages.

20 Tang QH, Li AJ, Yang GM et al. Surgical resection versus conformal radiotherapy combined with TACE for resectable hepatocellular carcinoma with portal vein tumor thrombus: a comparative study. World J. Surg. 37(6), 1362-1370 (2013).

21 Peng ZW, Guo RP, Zhang YJ, Lin XJ, Chen MS, Lau WY. Hepatic resection versus transcatheter arterial chemoembolization for the treatment of hepatocellular carcinoma with portal vein tumor thrombus. Cancer 118(19), 4725-4736 (2012).

22 Katagiri S, Yamamoto M. Multidisciplinary treatments for hepatocellular carcinoma with major portal vein tumor thrombus. Surg. Today 44(2), 219-226 (2014).

23 Demirjian A, Peng P, Geschwind JF et al. Infiltrating hepatocellular carcinoma: seeing the tree through the forest. J. Gastrointest. Surg. 15(11), 2089-2097 (2011).

24 Mehta N, Fidelman N, Sarkar M, Yao FY. Factors associated with outcomes and response to therapy in patients with infiltrative hepatocellular carcinoma. Clin. Gastroenterol. Hepatol. 11(5), 572-578 (2013).

25 Kim HY, Park JW, Nam BH et al. Survival of patients with advanced hepatocellular carcinoma: sorafenib versus other treatments.
J. Gastroenterol. Hepatol. 26(11), 1612-1618 (2011).

26 Jang ES, Yoon JH, Chung JW et al. Survival of infiltrative hepatocellular carcinoma patients with preserved hepatic function after treatment with transarterial chemoembolization. J. Cancer Res. Clin. Oncol. 139(4), 635-643 (2013).

27 Kokabi N, Camacho JC, Xing M et al. Apparent diffusion coefficient quantification as an early imaging biomarker of response and predictor of survival following yttrium-90 radioembolization for unresectable infiltrative hepatocellular carcinoma with portal vein thrombosis. Abdom. Imaging 39(5), 969-978 (2014).

28 Kokabi N, Galt JR, Xing M et al. A simple method for estimating dose delivered to hepatocellular carcinoma after yttrium-90 glass-based radioembolization therapy: preliminary results of a proof of concept study. J. Vasc. Interv. Radiol. 25(2), 277-287 (2014).

29 Raoul JL, Sangro B, Forner A et al. Evolving strategies for the management of intermediate-stage hepatocellular carcinoma: available evidence and expert opinion on the use of transarterial chemoembolization. Cancer Treat. Rev. 37(3), 212-220 (2011).

30 Lopez RR Jr, Pan SH, Hoffman AL et al. Comparison of transarterial chemoembolization in patients with unresectable, diffuse vs focal hepatocellular carcinoma. Arch. Surg. 137(6), 653-657; discussion 657-658 (2002).

31 Kneuertz PJ, Demirjian A, Firoozmand A et al. Diffuse infiltrative hepatocellular carcinoma: assessment of presentation, treatment, and outcomes. Ann. Surg. Oncol. 19(9), 2897-2907 (2012). 